\title{
Effects of Herbicides on Fusarium solani f. sp. glycines and Development of Sudden Death Syndrome in Glyphosate-Tolerant Soybean
}

\author{
S. Sanogo, X. B. Yang, and H. Scherm
}

Department of Plant Pathology, Iowa State University, Ames 50011.

Current address of H. Scherm: Department of Plant Pathology, University of Georgia, Athens 30602.

Accepted for publication 6 October 1999.

\begin{abstract}
Sanogo, S., Yang, X. B., and Scherm, H. 2000. Effects of herbicides on Fusarium solani f. sp. glycines and development of sudden death syndrome in glyphosate-tolerant soybean. Phytopathology 90:57-66.

Sudden death syndrome of soybean, caused by Fusarium solani f. sp. glycines, is a disease of increasing economic importance in the United States. Although the ecology of sudden death syndrome has been extensively studied in relation to crop management practices such as tillage, irrigation, and cultivar selection, there is no information on the effects of herbicides on this disease. Three herbicides (lactofen, glyphosate, and imazethapyr) commonly used in soybean were evaluated for their effects

celial growth, and sporulation in vitro were reduced by glyphosate and lactofen. In growth-chamber and greenhouse experiments, there was a significant increase in disease severity and frequency of isolation of $F$. solani f. sp. glycines from roots of all cultivars after application of imazethapyr or glyphosate compared with the control treatment (no herbicide applied). Conversely, disease severity and isolation frequency of $F$. solani f. sp. glycines decreased after application of lactofen. Across all herbicide treatments, severity of sudden death syndrome and isolation frequency were lower in disease-resistant than in susceptible cultivars. Results suggest that glyphosate-tolerant and -nontolerant cultivars respond similarly to infection by $F$. solani $\mathrm{f}$. sp. glycines after herbicide application.
\end{abstract} on the phenology of $F$. solani f. sp. glycines and the development of sudden death syndrome in four soybean cultivars varying in resistance to the disease and in tolerance to glyphosate. Conidial germination, my-
Additional keywords: Glycine max, herbicide stress.
The advent of herbicide-tolerant crop cultivars marked an important development in integrated crop management. Glyphosatetolerant cultivars were the first transgenic herbicide-tolerant cultivars to be introduced in soybean (Glycine max) production systems and were first grown commercially in 1996. Tolerance to glyphosate in these cultivars is effected through a single gene, the Roundup Ready gene (Monsanto Co., St. Louis), which was originally isolated from a glyphosate-tolerant soil bacterium (28). Cultivars with glyphosate tolerance are expected to improve weed control in soybean by allowing within-season applications of glyphosate any time from emergence through flowering, without plant injury or negative impacts on yield (8).

Despite their benefits, ethical and scientific concerns have been raised regarding the adoption of herbicide-tolerant crops (10). Because these crops are designed to take advantage of a single active ingredient, their wide adoption could lead to a monoherbicide cultural system, which may accelerate the development of herbicide resistance in weeds (29). Several studies have shown that herbicides can have inimical effects that lead to an increase in root diseases in various crops $(2,5)$. For example, glyphosate increased populations of various fungi in soil $(9,22,23,35)$. Glyphosate also can suppress plant defenses and enhance disease susceptibility in crops and weeds $(3,12,16,19,20,25,34,38)$. Furthermore, the herbicidal effect of glyphosate on glyphosate-nontolerant crops can be enhanced through parasitism by root-rot pathogens (15). If similar responses exist in glyphosate-tolerant crops, the benefit of herbicide tolerance could be reduced.

Corresponding author: X. B. Yang; E-mail address: xbyang @iastate.edu

Publication no. P-1999-1115-02R

(c) 2000 The American Phytopathological Society
Farmers and trade journals have raised concerns about increased prevalence of sudden death syndrome, caused by the soilborne fungus Fusarium solani f. sp. glycines (30-32), in glyphosate-tolerant soybean. However, no experimental data are available to validate these concerns. Sudden death syndrome generally occurs in fields with high yield potentials, where it can cause severe losses by reducing seed size and number. The disease has been extensively studied over the past two decades with respect to its etiology, epidemiology, and management (31). There is, however, no information on the effects of herbicides on this disease.

The objective of this study was to assess the effects of three selected herbicides on the phenology of $F$. solani f. sp. glycines and on the development of sudden death syndrome in four soybean cultivars varying in resistance to the disease and in tolerance to glyphosate.

\section{MATERIALS AND METHODS}

Fungal isolates and herbicides. Three isolates of $F$. solani $\mathrm{f}$. sp. glycines, two from Iowa (Clinton and Scott counties) and one from Illinois (Monticello), were used. Stock cultures were maintained on one-third-strength potato dextrose agar (PDA; $13 \mathrm{~g}$ of Difco potato dextrose and $14 \mathrm{~g}$ of agar per liter) at $22^{\circ} \mathrm{C}$.

Three formulated herbicides commonly used in soybean cultivation were tested: glyphosate (Roundup Ultra), imazethapyr (Pursuit 2 AS), and lactofen (Cobra 2 EC). Before use in laboratory studies, a stock solution of each herbicide was made and filtersterilized by passing the solution through a $0.22-\mu \mathrm{m}$ filter $(\mathrm{Co}-$ star Co., Cambridge, MA). The recommended field application rates $(1 \times)$ used for each formulated herbicide were $0.071,0.22$, and $0.84 \mathrm{~kg}$ a.i./ha for imazethapyr, lactofen, and glyphosate, respectively. 
Conidial germination. This experiment was completed three times; each completed experiment is referred to as a run. Conidia were produced by transferring a 5-mm plug from stock cultures onto full-strength PDA in 9-cm-diameter petri plates and placing the plates in an incubator at $22^{\circ} \mathrm{C}$ under $12 \mathrm{~h}$ of light. After 10 to 14 days, conidia were harvested by adding $15 \mathrm{ml}$ of sterile distilled water to each plate and gently scraping the medium surface with a soft paintbrush. The number of conidia was determined with a hemacytometer. To study the effects of herbicides on conidial germination, conidia were suspended in sterile distilled water (control) or in a solution of each herbicide at 0.5-, 1-, 2-, 5-, 10-, and 100 -fold the recommended field application rate on shallow-well microscope slides placed individually in 9-cm-diameter petri plates lined with moistened filter paper (Whatman No. 1, Whatman International, Maidstone, England). The plates were sealed with Parafilm and incubated in the dark at $22^{\circ} \mathrm{C}$ for $6 \mathrm{~h}$. In each well, 300 to 400 conidia were observed in random fields at $100 \times$. The proportion of germinated conidia was computed as the ratio of germinated conidia to observed conidia. The experiment was arranged in a completely randomized design with three replications, with the glass slide as the experimental unit.

Mycelial growth and sporulation. This experiment was conducted twice; each completed experiment is referred to as a run. To evaluate the effects of herbicides on growth and sporulation, PDA at three strengths $(3,33$, and $100 \% ; 100 \%$ was $39 \mathrm{~g} /$ liter $)$ was amended with each herbicide at 0- (control), 1-, 2-, and 10-fold the recommended field application rate. The medium was buffered with TES ( $N$-Tris(hydroxymethyl)methyl-2-amino ethanesulfonic acid; Sigma Chemical Co., St. Louis) as described by Jeffery and Burgess (14) to avoid confounding effects (i.e., different $\mathrm{pH}$ of the media due to different types and concentrations of herbicide). Each herbicide was added to cooled molten medium, mixed, and $20 \mathrm{ml}$ of the medium was poured into petri plates $(9 \mathrm{~cm}$ diameter $)$. The herbicide-amended plates were inoculated for $24 \mathrm{~h}$ after pouring by placing a $3-\mu \mathrm{l}$ drop of a conidial suspension $\left(10^{5}\right.$ conidia

TABLE 1. Mean squares (MS) and observed significance levels $(P)$ of the $F$ test for the effects of isolate, herbicide, herbicide concentration, and their interactions on in vitro conidial germination of Fusarium solani f. sp. glycines

\begin{tabular}{lrrr}
\hline & & \multicolumn{2}{c}{$\begin{array}{c}\text { Proportion of } \\
\text { Serminated conidia }\end{array}$} \\
\cline { 4 - 5 } Source of variation & a & MS & $P$ \\
\hline Isolate & 2 & 0.679 & 0.0055 \\
Herbicide & 2 & 93.371 & 0.0001 \\
Isolate-herbicide & 4 & 6.167 & 0.0001 \\
Herbicide concentration (concentration) & 6 & 58.627 & 0.0001 \\
Concentration-isolate & 12 & 1.081 & 0.0001 \\
Concentration-herbicide & 12 & 8.010 & 0.0001 \\
Concentration-herbicide-isolate & 24 & 0.751 & 0.0001 \\
\hline
\end{tabular}

a Data pooled across three runs (i.e., experiments). There were three isolate, three herbicide, and seven herbicide concentrations.

${ }^{\mathrm{b}}$ Data subjected to logit transformation before analysis. per $\mathrm{ml}$ ) of each isolate onto the center of each plate. The drops were allowed to dry and plates were sealed with Parafilm and incubated at $22^{\circ} \mathrm{C}$ in the laboratory under $12 \mathrm{~h}$ of light provided by cool-white fluorescent lamps. After 18 to 21 days, colony diameter was measured and colony area computed using the formula for the area of a circle. Conidia were harvested by adding $15 \mathrm{ml}$ of sterile distilled water per plate and gently scraping the medium surface with a soft paintbrush. The number of conidia was determined with a hemacytometer. The experiment was conducted as a split-plot arrangement of treatments in a completely randomized design with six replications, with plate as the experimental unit. Isolate (two isolates) and medium strength (three strengths) were assigned to whole plots, and herbicide treatment (10 treatments) to subplots. The 10 herbicide treatments were control (no herbicide added to medium), glyphosate, imazethapyr, and lactofen, each used at three concentrations $(1,2$, and $10 \times)$.
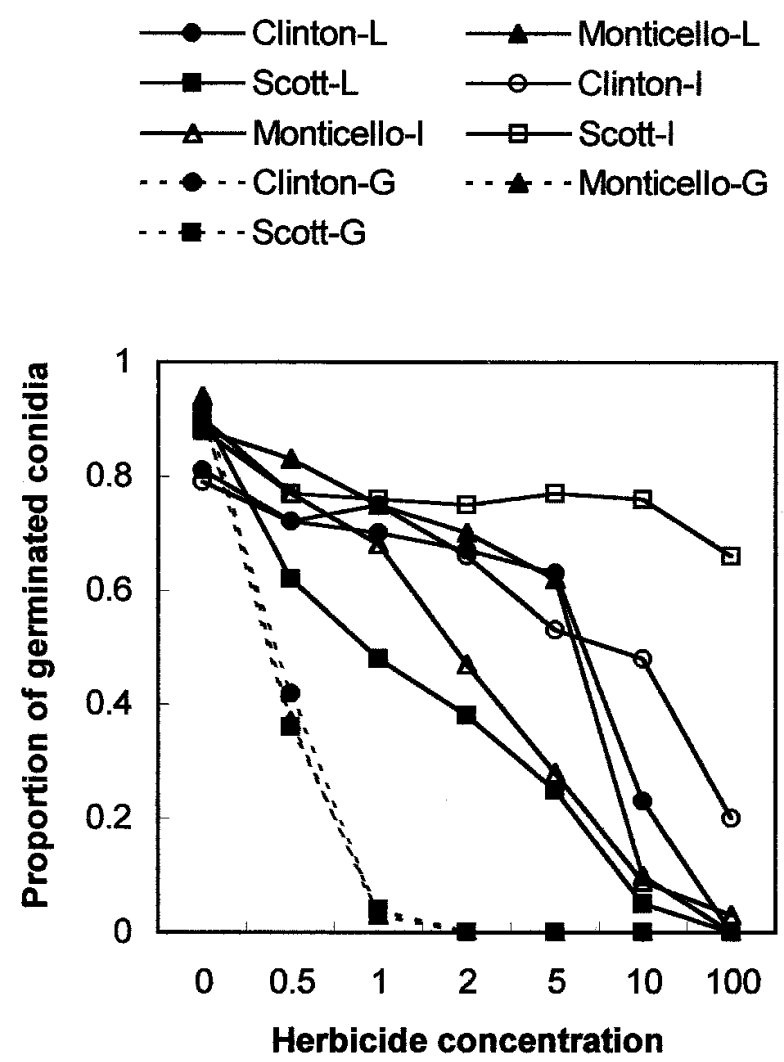

Fig. 1. Conidial germination of three isolates of Fusarium solani f. sp. glycines in a solution of three herbicides in vitro. Herbicide concentrations represent 0-, 0.5-, 1-, 2-, 5-, 10-, and 100-fold the recommended field application rate for each herbicide. Isolates are Clinton, Scott, and Monticello. Letters following the name of each isolate designate the herbicide: $\mathrm{L}=$ lactofen, $\mathrm{I}=$ imazethapyr, and $\mathrm{G}=$ glyphosate. Each data point is the mean of three runs (i.e., experiments) for a single isolate.

TABLE 2. Mean squares (MS) and observed significance levels $(P)$ of the $F$ test for the effects of growth medium strength, herbicide, and their interactions on colony area and sporulation of Fusarium solani f. sp. glycines

\begin{tabular}{|c|c|c|c|c|c|}
\hline \multirow[b]{2}{*}{ Source of variation $^{a}$} & \multirow[b]{2}{*}{ df } & \multicolumn{2}{|c|}{ Colony area } & \multicolumn{2}{|c|}{ Sporulation $^{\mathrm{b}}$} \\
\hline & & MS & $P$ & MS & $P$ \\
\hline Isolate & 1 & $11,382.953$ & 0.0001 & 0.188 & 0.4550 \\
\hline Medium strength & 2 & $15,176.227$ & 0.0001 & 229.064 & 0.0001 \\
\hline Herbicide & 9 & $2,221.553$ & 0.0001 & 0.386 & 0.0530 \\
\hline Isolate-medium strength & 2 & 166.282 & 0.0021 & 0.763 & 0.1227 \\
\hline Isolate-herbicide & 9 & 71.263 & 0.0012 & 0.314 & 0.1315 \\
\hline Medium strength-herbicide & 18 & 196.712 & 0.0001 & 0.688 & 0.0001 \\
\hline Isolate-medium strength-herbicide & 18 & 32.687 & 0.1135 & 0.241 & 0.6698 \\
\hline
\end{tabular}

a Data were pooled across two runs (i.e., experiments). There were 2 isolate, 3 medium strength, and 10 herbicide treatments.

${ }^{\mathrm{b}}$ Data were subjected to $\log$ (base e) transformation before analysis. 
Disease development in the growth chamber. Experiments were conducted in a growth chamber to assess the development of sudden death syndrome after foliar application of glyphosate, imazethapyr, and lactofen. The experiment was repeated three times; each completed experiment is referred to as a run. Clay pots $(10 \mathrm{~cm}$ diameter) were filled with $700 \mathrm{~g}$ (at $8 \%$ moisture-holding capacity) of a pasteurized 2:1 ( $\mathrm{vol} / \mathrm{vol}$ ) sand/soil mixture amended with conidial inoculum of $F$. solani f. sp. glycines (isolates Scott and
Monticello) at $4 \times 10^{4}$ conidia per $\mathrm{g}$. The soil used in this mixture was collected from a field cropped to soybean and has the following characteristics: $22.6 \%$ clay; $52.6 \%$ sand; $24.8 \%$ silt ( $\mathrm{pH} 8.1$ ); $7.9 \mathrm{ppm}$ of $\mathrm{NO}_{3}-\mathrm{N}$; and $2.2 \%$ organic matter. Inoculum was produced as described by Scherm and Yang (33). Three infestation treatments were established: noninfested (control), infested with isolate Scott, and infested with isolate Monticello. Three soybean cultivars, two tolerant to glyphosate (Pioneer 9344 and Asgrow 3701,
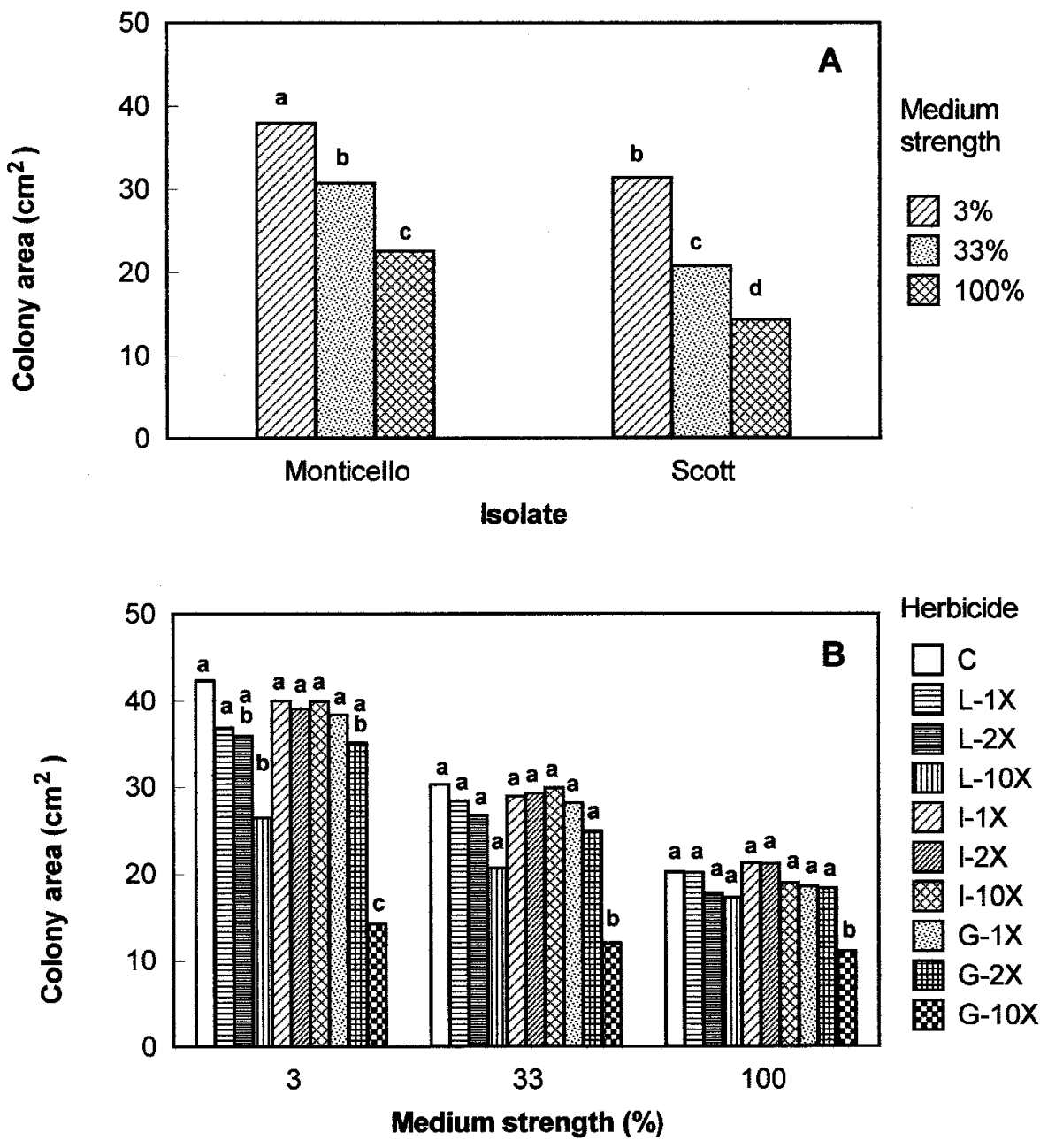

Herbicide

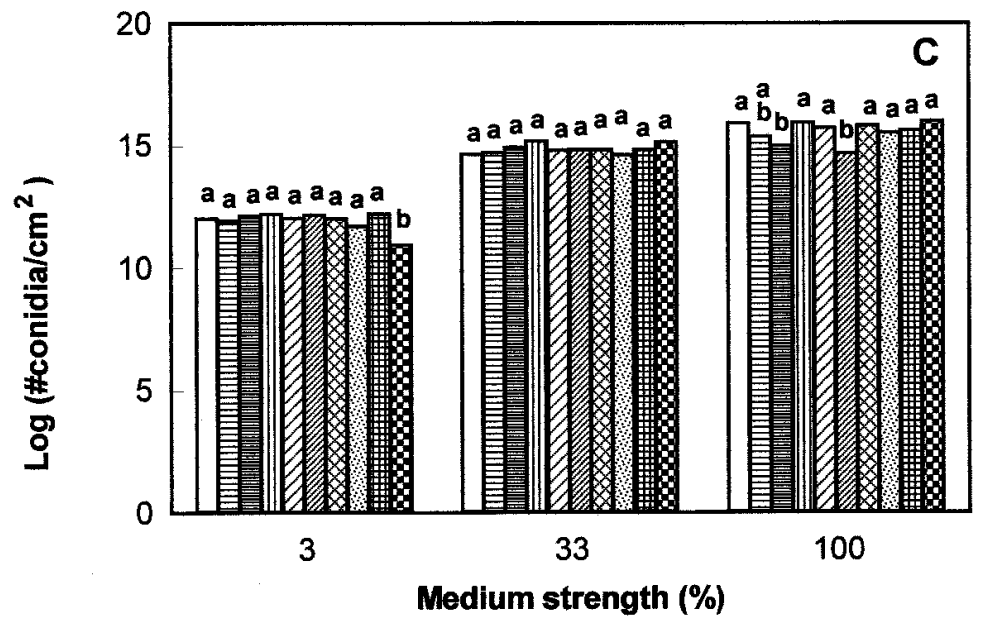

Herbicide

$\square \mathrm{C}$

$L-1 X$

$L-2 X$

血 L-10X

D $1-1 X$

漗 $L-2 X$

L-3X

\% $\mathrm{F}-1 X$

G-2X

G-10X

Medium strength (\%)

Fig. 2. Effect of growth medium strength, herbicide, and herbicide concentration on $\mathbf{A}$ and $\mathbf{B}$, colony area and $\mathbf{C}$, sporulation of Fusarium solani f. sp. glycines in vitro. Herbicide treatments are $\mathrm{C}=\mathrm{control}$ (no herbicide applied), $\mathrm{L}=$ lactofen, $\mathrm{I}=$ imazethapyr, and $\mathrm{G}=$ glyphosate. Values $1 \times, 2 \times$, and $10 \times$ represent $1-, 2-$, and 10-fold the recommended field application rate for each herbicide. Each bar is the mean of two runs (i.e., experiments). Across isolate (A) and within medium strength (B and C), bars with a common letter are not significantly different according to Fisher's protected least significant difference test at $P=0.05$. 
hereafter designated P9344 and A3701, respectively) and one nontolerant cultivar (BSR101), were planted. Cvs. P9344 and BSR101 are susceptible to sudden death syndrome, whereas cv. A3701 has above-average tolerance to the disease. Six seeds were planted per pot, and the pots were placed in a growth chamber at $20^{\circ} \mathrm{C}$ under $14 \mathrm{~h}$ of light. After emergence, plants were thinned to three per pot and fertilized weekly with $400 \mathrm{ppm}$ of $\mathrm{N}$ fertilizer $(20 \% \mathrm{~N}$, $20 \% \mathrm{P}_{2} \mathrm{O}_{5}$, and $20 \% \mathrm{~K}_{2} \mathrm{O}$; Peters Fertilizer Products, Fogelsville, PA). Plants at the V2 growth stage (11) were sprayed with glyphosate, lactofen, and imazethapyr at the recommended field application rate $(1 \times)$ as an aqueous solution, whereas those in control treatment were sprayed with distilled water. Foliar severity of sudden death syndrome was evaluated 14 days after herbicide application, using Horsfall and Barratt's scale (13). The experiment was conducted as a split-plot arrangement of treatments in a randomized complete block design with four replications, with the pot as the experimental unit. Infestation treatment (noninfested, infested with isolate Scott, and infested with isolate Monticello) and cultivar (P9344, A3701, and BSR101) were assigned to whole plots, and herbicide treatment (control, glyphosate, imazethapyr, and lactofen) was assigned to subplots.

Disease development in the greenhouse. This experiment was conducted twice; each completed experiment is referred to as a run. The experiment was identical to the growth-chamber experiment, except that (i) an additional soybean cultivar was used, Asgrow HIG3071 (hereafter designated A3071), an experimental line tolerant to glyphosate and resistant to sudden death syndrome; (ii) plants were inoculated at the $\mathrm{V} 3$ growth stage with $F$. solani f. sp. glycinescolonized oat kernels as described by Stephens et al. (36); and (iii) an additional herbicide concentration $(2 \times)$ equivalent to twice the recommended field application rate was included. Thus, the experiment involved three inoculation treatments (noninoculated, inoculated with Scott isolate, and inoculated with Monticello isolate), four cultivars (BSR101, P9344, A3701, and A3071), and seven herbicide treatments (sprayed with water, glyphosate at 1 and $2 \times$, lactofen at 1 and $2 \times$, and imazethapyr at 1 and $2 \times$ ). Air temper- ature in the greenhouse was 24 to $28^{\circ} \mathrm{C}$ during the day and 18 to $20^{\circ} \mathrm{C}$ during the night. Natural daylight in the greenhouse was supplemented with artificial light from high-intensity metal sodium bulbs to achieve a 14 -h photoperiod with a photon flux density of $340 \mu_{\mathrm{mol}}^{-2} \mathrm{~s}^{-1}$ at the top of the canopy. The experiment was conducted as a split-plot arrangement of treatments in a randomized complete block design with three replications, with the pot as the experimental unit. Inoculation treatment and cultivar were assigned to whole plots, and herbicide treatment was assigned to subplots.

Foliar severity of sudden death syndrome was evaluated 14 days after herbicide application using Horsfall and Barratt's scale (13). To characterize root colonization by $F$. solani f. sp. glycines, plants were uprooted and the roots were washed free of soil and scored for root rot severity using the same system used for scoring foliar severity. The roots were then air-dried for $72 \mathrm{~h}$, and five $1-\mathrm{cm}$ segments of taproot were removed from each plant (starting from the zone where the uppermost lateral root emerged). The segments were dipped and agitated in $1 \%$ tergitol solution for $2 \mathrm{~min}$, surfacesterilized in a 1:1 (vol/vol) mixture of $95 \%$ ethyl alcohol and $0.5 \%$ sodium hypochlorite $(\mathrm{NaOCl})$ for $4 \mathrm{~min}$, rinsed in sterile distilled water, and embedded in Nash-Snyder medium (26) in 9-cm-diameter plastic petri dishes. The dishes were sealed with Parafilm and incubated at room temperature $\left(20\right.$ to $\left.22^{\circ} \mathrm{C}\right)$ for 14 days, at which time the number of root segments yielding $F$. solani f. sp. glycines was recorded.

Shoot dry weights and type and severity of visual plant injury were recorded to quantify herbicide stress. Visual injury was assessed as the leaf area affected by each herbicide 7 days after application. Shoots were harvested in all treatments 7 days later, placed in an oven at $60^{\circ} \mathrm{C}$, and dry weights were recorded after $48 \mathrm{~h}$. A shoot dry weight index (17) was computed by dividing the mean shoot dry weight in each treatment by that of the control treatment (noninoculated plants sprayed with water).

Data analysis. The data sets obtained in the various experiments conducted in this study consisted of the following: (i) pro-

TABLE 3. Mean squares (MS) and observed significance levels $(P)$ of the $F$ test for the effects of soil infestation with Fusarium solani f. sp. glycines, cultivar, herbicide treatment, and their interactions on severity of sudden death syndrome of soybean in a growth chamber

\begin{tabular}{|c|c|c|c|c|c|}
\hline \multirow[b]{2}{*}{ Source of variation ${ }^{\mathrm{a}}$} & \multirow[b]{2}{*}{$\mathrm{df}$} & \multicolumn{2}{|c|}{ Foliar disease severity ${ }^{\mathrm{b}}$} & \multicolumn{2}{|c|}{ Root disease severity ${ }^{\mathrm{b}}$} \\
\hline & & MS & $P$ & MS & $P$ \\
\hline Isolate & 1 & 129.660 & 0.0012 & 484.603 & 0.0025 \\
\hline Cultivar & 2 & 8.565 & 0.0091 & 9.346 & 0.0285 \\
\hline Herbicide & 3 & 28.624 & 0.0001 & 10.466 & 0.0003 \\
\hline Herbicide-isolate & 3 & 6.507 & 0.0056 & 3.633 & 0.0034 \\
\hline Herbicide-cultivar & 6 & 0.684 & 0.0896 & 1.755 & 0.0025 \\
\hline Herbicide-isolate-cultivar & 6 & 0.724 & 0.2963 & 2.521 & 0.0028 \\
\hline
\end{tabular}

a Data were pooled across three runs (i.e., experiments). Run was considered a random effect, and all interactions were tested with the appropriate run-interaction mean square. There were two isolate, three cultivar, and four herbicide treatments.

${ }^{b}$ Data were subjected to square-root transformation before analysis.

TABLE 4. Mean squares (MS) and observed significance levels $(P)$ of the $F$ test for the effects of isolate, cultivar, herbicide treatment, and their interactions on severity of sudden death syndrome and root colonization of soybean by Fusarium solani f. sp. glycines in a greenhouse

\begin{tabular}{|c|c|c|c|c|c|c|c|}
\hline \multirow[b]{2}{*}{ Source of variation $^{a}$} & \multirow[b]{2}{*}{$\mathrm{df}$} & \multicolumn{2}{|c|}{ Foliar disease severity } & \multicolumn{2}{|c|}{ Root disease severity ${ }^{\mathrm{b}}$} & \multicolumn{2}{|c|}{ Isolation frequency } \\
\hline & & MS & $P$ & MS & $P$ & MS & $P$ \\
\hline Inoculation & 1 & $5,576.582$ & 0.0328 & 42.058 & 0.0230 & $15,927.116$ & 0.0055 \\
\hline Cultivar & 3 & $11,978.215$ & 0.0004 & 7.600 & 0.0004 & $13,038.580$ & 0.0001 \\
\hline Herbicide & 6 & 814.784 & 0.0001 & 0.456 & 0.0001 & $1,212.169$ & 0.0001 \\
\hline Herbicide-inoculation & 6 & 6.126 & 0.9283 & 0.013 & 0.5423 & 13.227 & 0.6595 \\
\hline Herbicide-cultivar & 18 & 68.634 & 0.0001 & 0.007 & 0.4767 & 100.411 & 0.0001 \\
\hline Herbicide-inoculation-cultivar & 18 & 15.328 & 0.3678 & 0.016 & 0.0358 & 14.932 & 0.0463 \\
\hline
\end{tabular}

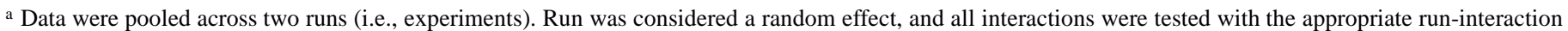

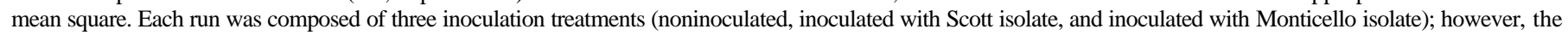
noninoculated treatment was not included in analysis of variance. There were four cultivar and seven herbicide treatments.

b Data were subjected to log (base e) transformation before analysis. 
portion of conidia that germinated in herbicide solution; (ii) colony area and number of conidia per colony area; (iii) foliar and root severity of sudden death syndrome in the growth chamber study; (iv) foliar and root severity of sudden death syndrome, frequency of isolation of $F$. solani f. sp. glycines from roots, and shoot dry weight index in the greenhouse study. Each data set was sub-
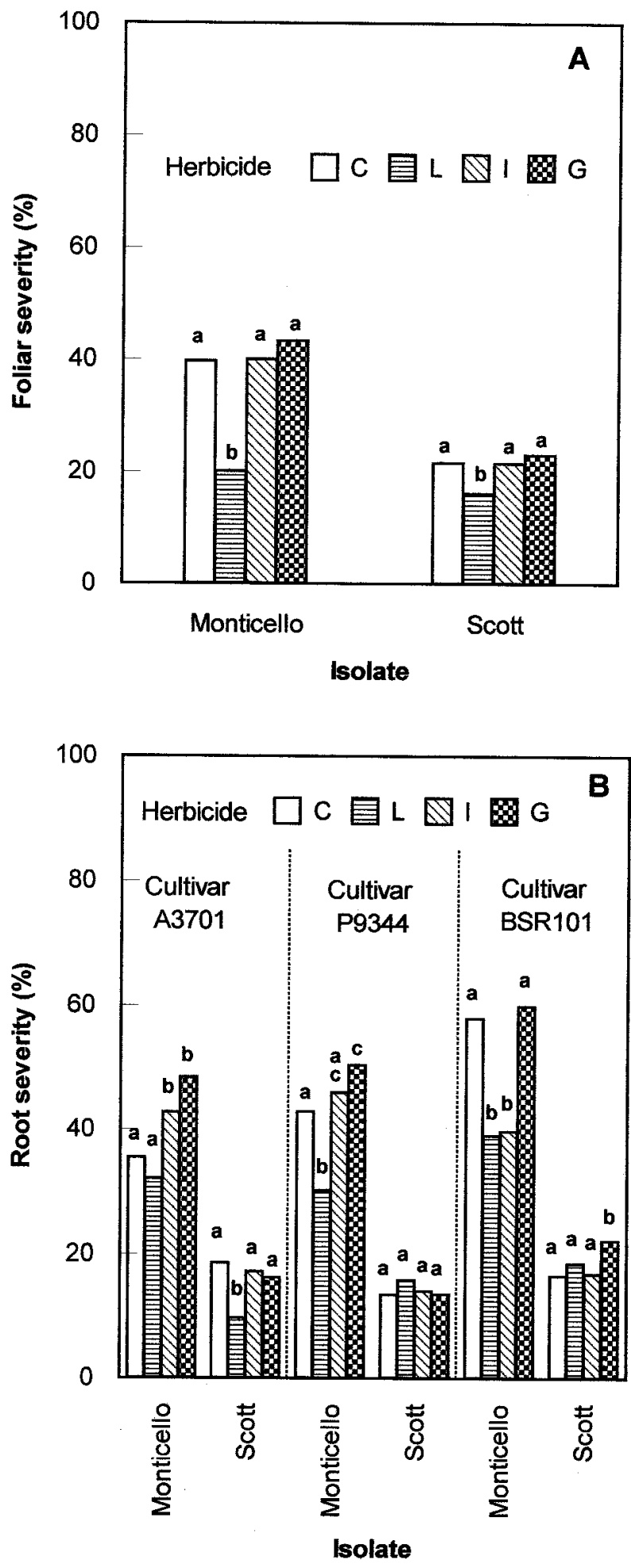

Fig. 3. Effect of herbicides on A, foliar and $\mathbf{B}$, root severity of sudden death syndrome in soybean grown in soil infested with Fusarium solani f. sp. glycines in a growth chamber. Herbicide treatments are $\mathrm{C}=$ control, $\mathrm{L}=$ lactofen, $\mathrm{I}=$ imazethapyr, and $\mathrm{G}=$ glyphosate. Each bar is the mean of three runs (i.e., experiments). Within isolate (A) and within each cultivar-isolate (B), bars with a common letter are not significantly different according to Fisher's protected least significant difference test at $P=0.05$. jected to analysis of variance to test the significance of all factors examined in each experiment. $F$ tests were done to determine homogeneity of error variances among runs (27), and data were pooled across runs accordingly for final analyses. To satisfy the assumptions of homogeneity and normality of error variances of the analysis of variance, the following transformations were applied to data sets: (i) logit transformation of the proportion of conidia that germinated in herbicide solution; (ii) log (base e) transformation of the number of conidia per colony area; (iii) squareroot transformation of the foliar and root severity of sudden death syndrome in the growth chamber study; and (iv) log (base e) transformation of the root severity of sudden death syndrome and of the shoot dry weight index in the greenhouse study. Treatment means were separated using Fisher's protected least significant difference test at the 5\% significance level.

\section{RESULTS}

Conidial germination. There was a significant interactive effect of isolate, herbicide, and herbicide concentration on germination of conidia (Table 1). Of the herbicides tested, glyphosate had the strongest effect (Fig. 1), reducing germination by 94 to $98 \%$ across all isolates when used at the $1 \times$ concentration. In contrast, conidial germination was reduced by only 8 to $48 \%$ with imazethapyr or lactofen at the recommended field application rate $(1 \times)$. In lactofen and glyphosate, the reduction in germination with increasing herbicide concentration was similar for the three isolates of $F$. solani f. sp. glycines (Fig. 1A and C), whereas in imazethapyr the Scott isolate responded less strongly than the other two isolates to increasing concentration (Fig. 1).

Mycelial growth and sporulation. Colony area of $F$. solani $\mathrm{f}$. sp. glycines was significantly affected by isolate, growth medium strength, and herbicide treatment (Table 2). Overall, colony area was greatest at low medium strength and decreased with increasing medium strength (Fig. 2A). Colony area was most strongly affected on 3\% PDA when medium was amended with lactofen or glyphosate compared with control medium or medium amended with imazethapyr (Fig. 2B). On 33 and 100\% PDA, only glyphosate at $10 \times$ concentration significantly reduced colony area (Fig. $2 \mathrm{~B})$. In contrast to colony area, the total number of conidia produced per unit of colony area tended to increase with increasing medium strength. The only statistically significant interaction was between herbicide and medium strength (Table 2 and Fig. 2C). The interaction was due to a lack of difference among herbicide treatments on 33\% PDA, whereas there was a significant decrease in sporulation when 3\% PDA was amended with glyphosate at $10 \times$ concentration and when $100 \%$ PDA was amended with lactofen and imazethapyr.

TABLE 5. Mean squares (MS) and observed significance levels $(P)$ of the $F$ test for the effects of inoculation with Fusarium solani f. sp. glycines, cultivar, herbicide treatment, and their interactions on shoot dry weight of soybean in a greenhouse

\begin{tabular}{lrcc}
\hline & & \multicolumn{2}{c}{ Shoot dry weight ${ }^{\mathrm{b}}$} \\
\cline { 3 - 4 } Source of variation $^{\mathrm{a}}$ & df & MS & $P$ \\
\hline Inoculation & 2 & 1.684 & 0.0001 \\
Cultivar & 3 & 1.108 & 0.0001 \\
Inoculation-cultivar & 6 & 0.045 & 0.0156 \\
Herbicide & 6 & 0.787 & 0.0001 \\
Herbicide-inoculation & 12 & 0.031 & 0.0308 \\
Herbicide-cultivar & 18 & 0.060 & 0.0001 \\
Herbicide-inoculation-cultivar & 36 & 0.007 & 0.9941 \\
\hline
\end{tabular}

${ }^{a}$ Data were pooled across two runs (i.e., experiments). Run was considered a random effect, and all interactions were tested with the appropriate run-interaction mean square. Inoculation treatments were noninoculated, inoculated with Scott isolate, and inoculated with Monticello isolate. There were four cultivar and seven herbicide treatments.

${ }^{\mathrm{b}}$ Data were subjected to log (base e) transformation before analysis. 

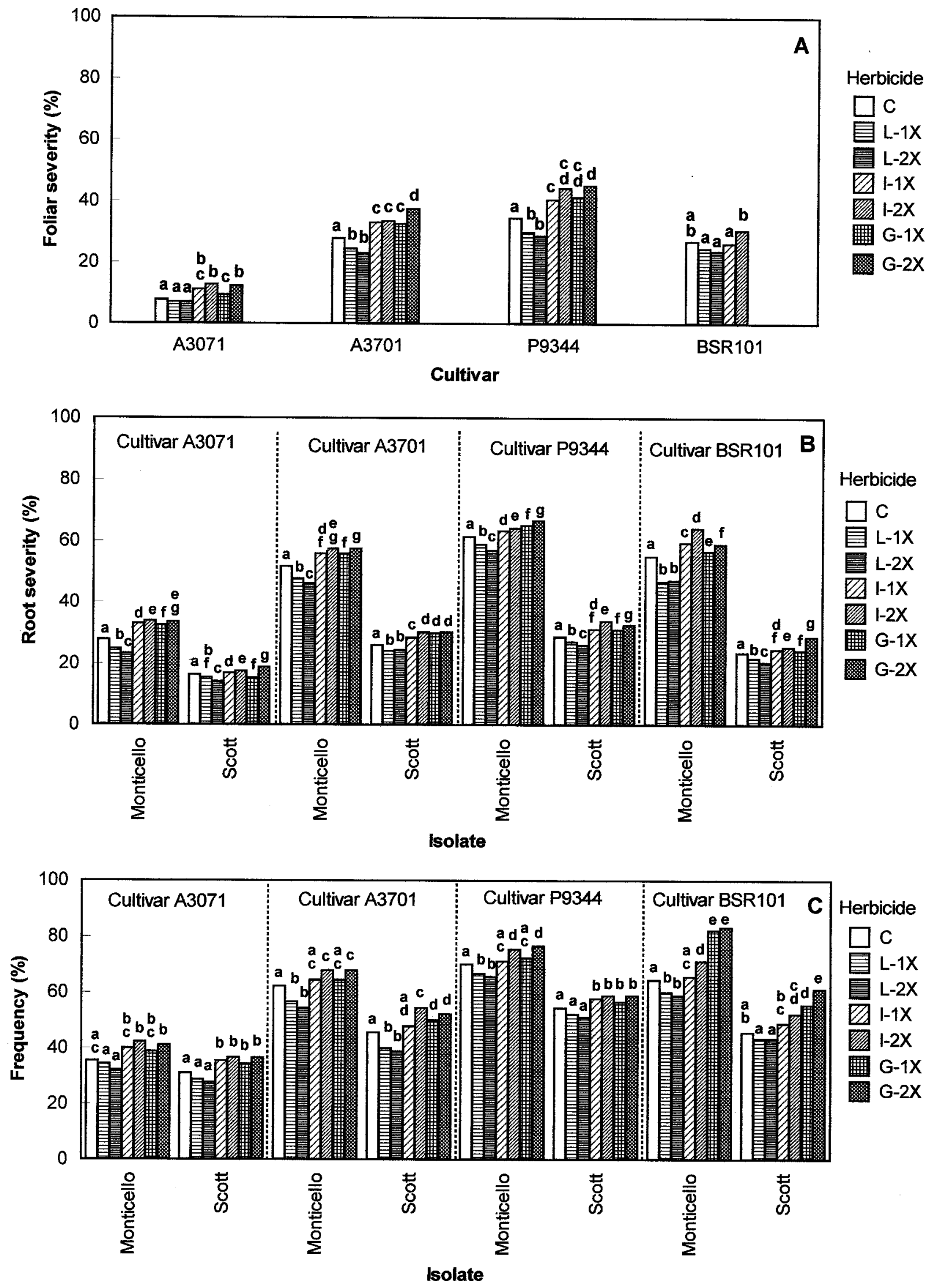

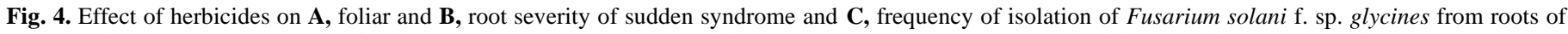

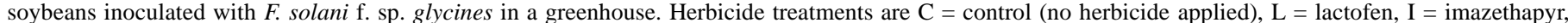

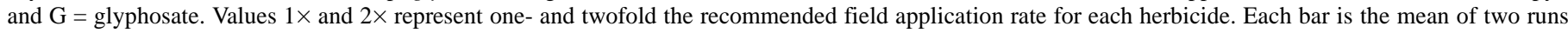

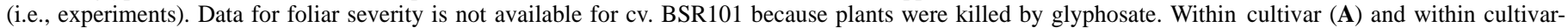
isolate $(\mathbf{B}$ and $\mathbf{C})$, bars with a common letter are not significantly different according to Fisher's protected least significant difference test at $P=0.05$. 
Disease development in the growth chamber. Analysis of variance revealed statistically significant interaction of isolate-cultivar and herbicide-isolate for foliar disease severity (Table 3). Foliar severity of sudden death syndrome was significantly decreased after lactofen application (Fig. 3A). Conversely, plants treated with glyphosate and imazethapyr had levels of foliar disease severity similar to the control. In glyphosate-tolerant cultivars (A3701 and A9344) and depending on isolates, root rot severity was significantly de- creased in plants sprayed with lactofen, and significantly increased in plants treated with glyphosate and imazethapyr (Fig. 3B). In cv. BSR101 growing in soil infested with Monticello isolate, root-rot severity was decreased with lactofen and imazethapyr compared with control and glyphosate-treated plants (Fig. 3B). However, when BSR101 was grown in soil infested with Scott isolate, there was a significant increase in root rot severity in plants treated with glyphosate compared with other herbicides.

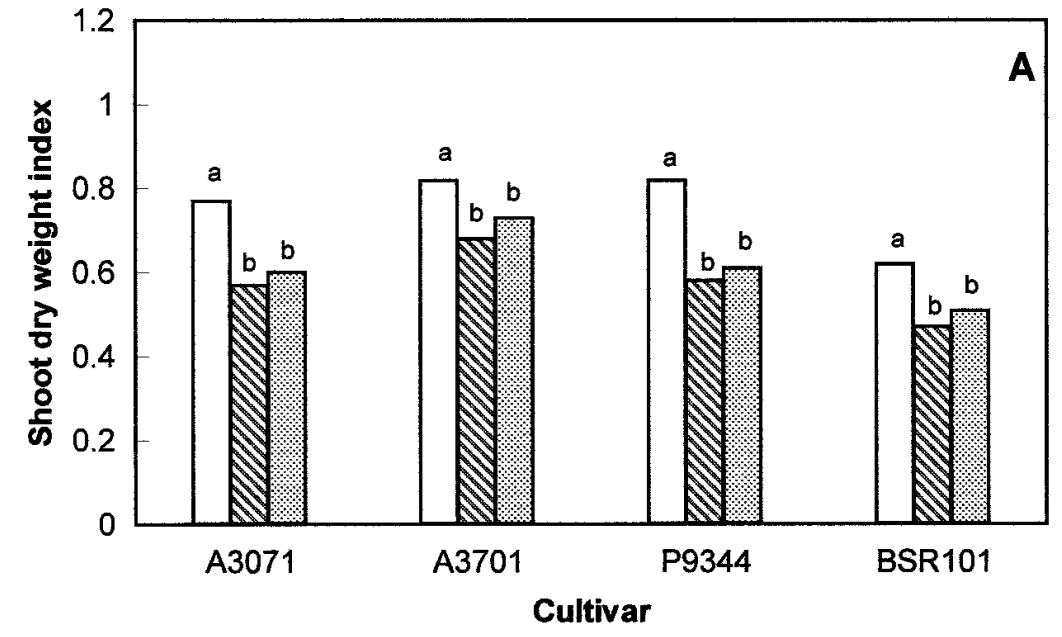

Isolate
$\square$ Noninoculated
Monticello
Scott
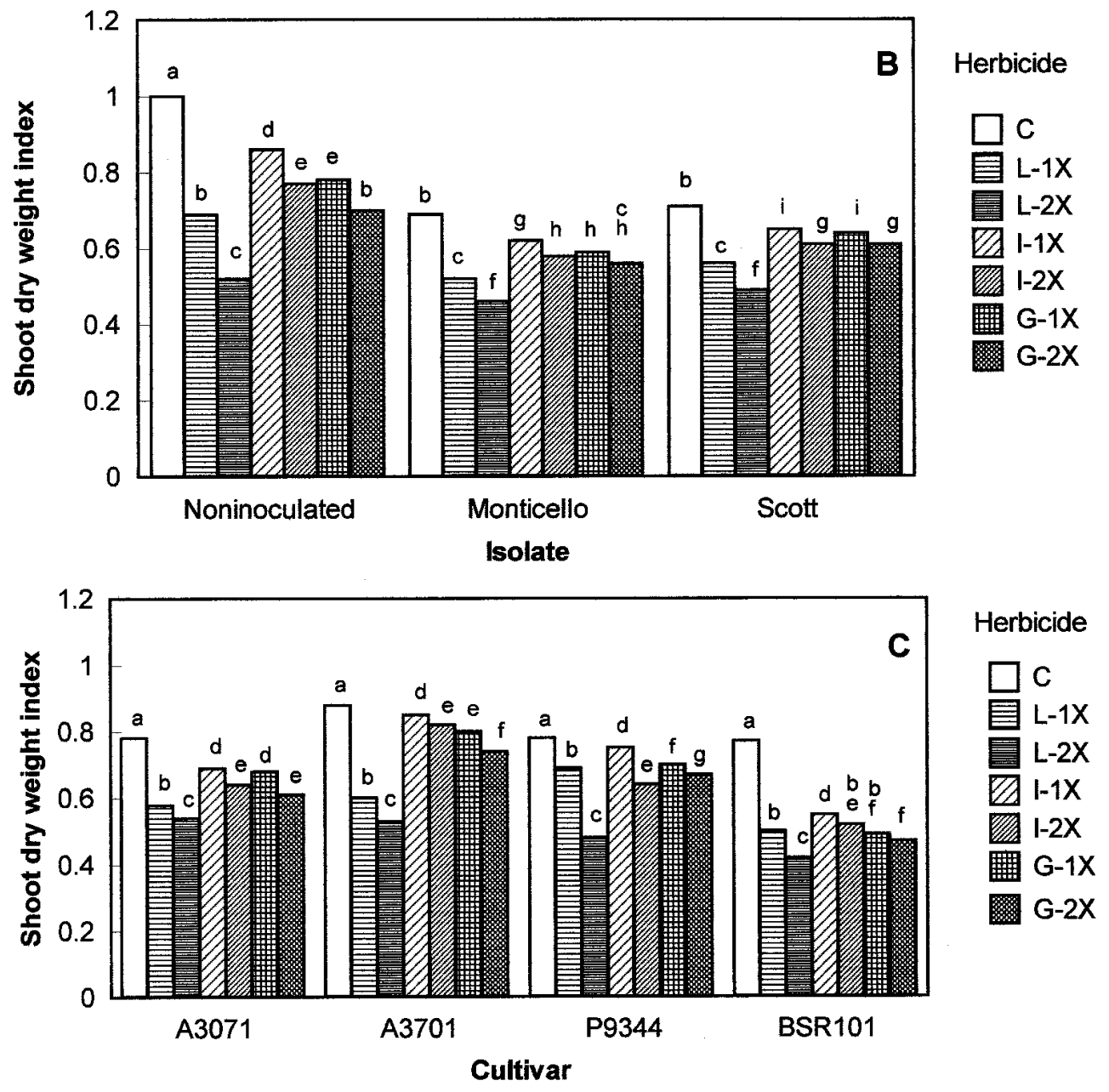

Fig. 5. Interactive effects of $\mathbf{A}$, cultivar-isolate, $\mathbf{B}$, isolate-herbicide, and $\mathbf{C}$, isolate-herbicide on shoot dry-weight index in soybeans inoculated with Fusarium solani f. sp. glycines in a greenhouse. Herbicide treatments are $\mathrm{C}=$ control (no herbicide applied), $\mathrm{L}=$ lactofen, $\mathrm{I}=$ imazethapyr, and $\mathrm{G}=\mathrm{glyphosate}$. Values $1 \times$ and $2 \times$ represent one- and twofold the recommended field application rate for each herbicide. Each bar is the mean of two runs (i.e., experiments). Within cultivar (A and C) and across isolate (B), bars with a common letter are not significantly different according to Fisher's protected least significant difference test at $P=0.05$. 
Disease development in the greenhouse. There was a significant herbicide-inoculation-cultivar interaction for root rot severity $(P=0.0358)$ and frequency of isolation of $F$. solani f. sp. glycines from roots $(P=0.0463)$, indicating that herbicide effects varied over inoculation and cultivar treatments (Table 4). However, this interaction term was not statistically significant for foliar disease severity $(P=0.3678)$. In lactofen-treated plants, disease severity and isolation frequency (Fig. 4) were similar to or significantly lower than in the controls. Conversely, in plants sprayed with imazethapyr and glyphosate, disease severity and isolation frequency from roots were significantly increased compared with the controls and lactofentreated plants. Overall, foliar and root disease severity and isolation frequency from roots were higher in cvs. A3701, BSR101, and P9344 than in A3071.

There were significant two-way interactions among inoculation, cultivar, and herbicide treatments for shoot dry-weight index (Table 5). Compared with noninoculated plants, shoot dry-weight index was significantly decreased in inoculated plants (Fig. 5A and B), and this decrease was further deepened when inoculated plants were sprayed with herbicides (Fig. 5B). Shoot dry-weight index was significantly decreased with all herbicides compared with control (no herbicide applied), and the decrease was greater in plants sprayed with lactofen than in plants sprayed with glyphosate or imazethapyr (Fig. 5C).

Herbicide injury. The type and severity of visually apparent injury after application of the three herbicides are summarized in Table 6. Lactofen caused the most severe damage across all cultivars, resulting in injury characterized by brown necrotic leaf spots accompanied by slight cupping of younger leaves. No visual injury was noted after application of imazethapyr. Glyphosate did not cause any visible injury on glyphosate-tolerant cultivars, but on the nontolerant cultivar (BSR101), increasing chlorosis developed, followed by wilting and plant death. Death occurred approximately 5 days earlier in inoculated than in noninoculated plants.

\section{DISCUSSION}

The present study is part of a research program aimed at evaluating the impact of herbicides and herbicide-tolerant soybeans on root disease development. The impetus for examining the interaction of $F$. solani f. sp. glycines with glyphosate-tolerant soybeans emanated from concerns raised about the perceived increase in prevalence of sudden death syndrome in such cultivars after application of glyphosate. Results suggest that glyphosate-tolerant and -nontolerant cultivars respond similarly to infection by $F$. solani $\mathrm{f}$. sp. glycines after herbicide application.

The effects of herbicides on disease development generally result from interactions between direct effects on the pathogen and indirect effects via plant-mediated responses. When direct effects of herbicides on $F$. solani f. sp. glycines were examined in vitro, glyphosate showed inhibitory effects on spore germination and mycelial growth. In addition, mycelial growth also was affected by medium strength and herbicide concentration, and there was a significant herbicide-medium strength interaction. Other studies also demonstrated interactive effects of medium strength and herbicide concentration on growth of plant pathogens. Campbell and Altman (4) found that mycelial growth of Rhizoctonia solani on herbicide-amended PDA increased as PDA strength was reduced from 100 to $10 \%$. Jeffery and Burgess (14) observed that nutrient levels in culture media affected the influence of herbicides on growth of $F$. graminearum. The use of varying strengths of growth medium could be thought of as representing different nutritional levels of tissue as it may be expected in plants at different stages of growth and development. The range of herbicide concentrations used was selected to represent what would be encountered in production fields at recommended application rate $(1 \times)$, accidental overlap of spray coverage $(2 \times)$, and accumulation or spill $(10 \times)$. It was assumed that the pathogen would be subjected to herbicide adsorbed from spray solution and released by vegetation residues on and in the soil, and through translocation of the active ingredient via the roots $(1,6,24,37)$.

Stresses imposed by herbicides in conjunction with physical factors can indirectly lead to increased disease in crops (2). Indeed, herbicide stress weakens and predisposes plants to rapid fungal colonization $(2,5)$. Conceptually, the use of herbicide-tolerant crops, such as glyphosate-tolerant soybeans, could reduce damage from herbicide stress-related diseases that are observed in conventional cultivars after herbicide application $(2,5)$. However, it appears from this study that glyphosate tolerance does not translate into stress reduction to a level that minimizes sudden death syndrome in glyphosate-tolerant cultivars after glyphosate application compared with glyphosate-tolerant or -nontolerant cultivars sprayed with imazethapyr or lactofen. The existence of herbicide stress could explain the significant increase in disease severity and pathogen isolation frequency following application of glyphosate or imazethapyr. For lactofen, however, there was a significant decrease in disease severity and pathogen isolation frequency after application, despite visually apparent herbicide stress. Lactofen, a diphenyl-ether herbicide with limited translocation activity, has been shown to reduce severity of white mold (caused by Sclerotinia sclerotiorum) by $50 \%$ in treated soybean compared with water-sprayed plants (7). Further, on leaves inoculated with mycelium of S. sclerotiorum and treated with lactofen, lesion size was smaller than on those untreated with lactofen. It has also been reported that lactofen consistently increased yield and reduced white mold incidence in susceptible cultivars under high disease pressure (39). Lactofen induces plant-mediated responses, such as production of glyceollin, that are involved in disease suppression. High levels of glyceollin were found in lactofen-treated leaves, whereas in nontreated leaves glyceollin was undetectable $(7,21)$. It is plausible that lactofen may induce similar responses in plants infected with $F$. solani f. sp. glycines, which may explain the fact that disease severity was lower in lactofen-sprayed plants than in those sprayed with other herbicides.

The effects of glyphosate, imazethapyr, and lactofen on infection by $F$. solani f. sp. glycines have not been previously examined. Although comparisons can be made to results obtained with other formae speciales of $F$. solani, there are important contextual differences among the studies. For example, Kawate et al. (18)

TABLE 6. Visual injury in glyphosate-tolerant (GT) and -nontolerant (NGT) soybean cultivars after application of three herbicides

\begin{tabular}{|c|c|c|c|c|c|}
\hline \multirow[b]{2}{*}{ Herbicide } & \multirow{2}{*}{$\begin{array}{c}\text { Herbicide } \\
\text { concentration }^{\mathrm{a}}\end{array}$} & \multicolumn{2}{|c|}{ Injury symptom type } & \multicolumn{2}{|c|}{ Injury severity $(\%)^{\mathrm{b}}$} \\
\hline & & GT & NGT & GT & NGT \\
\hline \multirow[t]{2}{*}{ Lactofen } & $1 \times$ & Necrosis & Necrosis & 25 & 25 \\
\hline & $2 \times$ & Necrosis & Necrosis & 35 & 35 \\
\hline \multirow[t]{2}{*}{ Imazethapyr } & $1 \times$ & No injury & No injury & 0 & 0 \\
\hline & $2 x$ & No injury & No injury & 0 & 0 \\
\hline \multirow[t]{2}{*}{ Glyphosate } & $1 \times$ & No injury & Chlorosis and death & 0 & 40 \\
\hline & $2 x$ & No injury & Chlorosis and death & 0 & 60 \\
\hline
\end{tabular}

a Concentrations represent one- and twofold the recommended field rate for each herbicide.

${ }^{\mathrm{b}}$ Percent leaf area with necrosis or chlorosis. 
found that pathogenicity of $F$. solani f. sp. pisi on green pea (Pisum sativum) was not affected when conidia used for inoculation were produced on glyphosate-amended growth media. Although the latter study suggests that glyphosate would have little direct effect on propagules of $F$. solani f. sp. glycines, it does not provide any information on the effect of glyphosateinduced plant stress on root rot development because glyphosate was not applied in planta.

Application of the three herbicides resulted in a decrease in plant dry weight with greater magnitude in inoculated than in noninoculated plants. Furthermore, in glyphosate-treated BSR101 plants, death occurred earlier in inoculated than in noninoculated plants. These results indicate that plant parasitism enhances herbicidal activity. Johal and Rahe (15) first demonstrated this phenomenon in relation to glyphosate and referred to it as glyphosate synergistic interaction. It appears from this study that enhancement of herbicidal activity by parasitism is not limited to glyphosate.

The results of this study are important to management of sudden death syndrome in glyphosate-tolerant and -nontolerant soybeans in relation to the use of herbicides and disease resistance. Although severity of sudden death syndrome was reduced more in disease-resistant than susceptible cultivars across all herbicide treatments, the use of resistant cultivars is unlikely to counteract potentially negative impacts (plant or soil microflora-mediated) from excessive herbicide application.

\section{ACKNOWLEDGMENTS}

Journal Paper J-18383 of the Iowa Agriculture and Home Economics Experiment Station, Ames, Project 2869. Supported by the Hatch Act and State Iowa funds, the Iowa Soybean Promotion Board, and the North Central IPM Program. We thank C. M. Peters, C. King, and P. Vance for technical assistance.

\section{LITERATURE CITED}

1. Ahearn-Meyerson, L., McLain, J. E. T., Mayfield, A. E., and Berlyn, G. P. 1997. Bioassays suggest that glyphosate persists in soil long enough to kill seedlings. Restoration Manage. Notes 15:200-201.

2. Altman, J., and Rovira, A. D. 1989. Herbicide-pathogen interactions in soil-borne root diseases. Can. J. Plant Pathol. 11:166-172.

3. Brammall, R. A., and Higgins, V. J. 1987. The effect of glyphosate on resistance of tomato to Fusarium crown and root rot disease and on the formation of host structural defensive barriers. Can. J. Bot. 66:15471555.

4. Campbell, C. L., and Altman, J. 1977. Pesticide-plant disease interactions: Effect of cycloate on growth of Rhizoctonia solani. Phytopathology 67: 557-560.

5. Canaday, C. H., Helsel, D. G., and Wyllie, T. D. 1986. Effects of herbicide-induced stress on root colonization of soybeans by Macrophomina phaseolina. Plant Dis. 70:863-866.

6. Coupland, D., and Peabody, D. V. 1981. Absorption, translocation, and exudation of glyphosate, fosamine, and amitrole in field horsetail (Equisetum arvense). Weed Sci. 29:556-560.

7. Dann, E. K., Diers, B. W., and Hammerschmidt, R. 1999. Suppression of white mold disease in soybeans by lactofen herbicide treatment. Phytopathology 89:598-602.

8. Delannay, X., Bauman, T. T., Beighley, D. H., Buettner, M. J., Coble, H. D., DeFelice, M. S., Derting, C. W., Diedrick, T. J., Griffin, J. L., Hagood, E. S., Hancock, F. G., Hart, S. E., LaVallee, B. J., Loux, M. M., Lueschen, W. E., Matson, K. W., Moots, C. K., Murdock, F. G., Nickell, A. D., Owen, M. D. K., Paschal, E. H., II, Prochaska, L. M., Raymond, P. J., Reynolds, D. B., Rhodes, W. K., Roeth, F. W., Sprankle, P. L., Tarochione, L. J., Tinius, C. N., Walker, R. H., Wax, L. M., Weigelt, H. D., and Padgette, S. R. 1995. Yield evaluation of a glyphosate-tolerant soybean line after treatment with glyphosate. Crop Sci. 35:1461-1467.

9. Descalzo, R. C., Punja, Z. K., Levesque, C. A., and Rahe, J. E. 1998. Glyphosate treatment of bean seedlings causes short-term increases in Pythium populations and damping off potential in soils. Appl. Soil Ecol. 8:25-33.

10. Duke, S. O., ed. 1996. Herbicide-Resistant Crops: Agricultural, Environmental, Economic, Regulatory, and Technical Aspects. Lewis Publishers, Boca Raton, FL.
11. Fehr, W. R., Caviness, C. E., Burmood, D. T., and Pennington, J. S. 1971. Stage of development descriptions for soybeans, Glycine max (L.) Merrill. Crop Sci. 11:929-931.

12. Holliday, M. J., and Keen, N. T. 1982. The role of phytoalexins in the resistance of soybean leaves to bacteria: Effects of glyphosate on glyceollin accumulation. Phytopathology 72:1470-1470.

13. Horsfall, J. G., and Barratt, R. W. 1945. An improved grading system for measuring plant disease. (Abstr.) Phytopathology 35:655.

14. Jeffery, S., and Burgess, L. W. 1990. Growth of Fusarium graminearum Schwabe group I on media amended with atrazine, chlorosulfuron or glyphosate in relation to temperature and osmotic potential. Soil Biol. Biochem. 22:665-670.

15. Johal, G. S., and Rahe, J. E. 1984. Effect of soilborne plant pathogenic fungi on the herbicidal action of glyphosate on bean seedlings. Phytopathology 74:950-955.

16. Johal, G. S., and Rahe, J. E. 1990. Role of phytoalexins in the suppression of resistance of Phaseolus vulgaris to Colletotrichum lindemuthianum by glyphosate. Can. J. Plant Pathol. 12:225-235.

17. Karr, G. W., Jr., Gudauskas, R. T., and Dickens, R. 1979. Effects of three herbicides on selected pathogens and diseases of turfgrasses. Phytopathology 69:279-282.

18. Kawate, M. K., Kawate, S. C., Ogg, A. G., Jr., and Kraft, J. M. 1992. Response of Fusarium solani f. sp. pisi and Pythium ultimum to glyphosate. Weed Sci. 40:497-502.

19. Keen, N. T., Holliday, M. J., and Yoshikawa, M. 1982. Effects of glyphosate on glyceollin production and the expression of resistance to Phytophthora megasperma f. sp. glycinea in soybean. Phytopathology 72:14671470.

20. Latunde-Dada, A. O., and Lucas, J. A. 1985. Involvement of the phytoalexin medicarpin in the differential response of callus lines of lucerne (Medicago sativa) to infection by Verticillium albo-atrum. Physiol. Plant Pathol. 26:31-42.

21. Levene, B. C., Owen, M. D. K., and Tylka, G. L. 1998. Response of soybean cyst nematodes and soybeans (Glycine max) to herbicides. Weed Sci. 46:264-270.

22. Lévesque, C. A., Rahe, J. E., and Eaves, D. M. 1987. Effects of glyphosate on Fusarium spp.: Its influence on root colonization of weeds, propagule density in the soil, and crop emergence. Can. J. Microbiol. 33:354360.

23. Lynch, J. M., and Penn, D. J. 1980. Damage to cereals caused by decaying weed residues. J. Sci. Food Agric. 31:321-324.

24. Marshall, G., Kirkwood, R. C., and Martin, D. J. 1987. Studies of the mode of action of asulam, aminotriazole and glyphosate in Equisetum arvense L. (field horsetail): I. The uptake and translocation of $\left[{ }^{14} \mathrm{C}\right]$ asulam, $\left[{ }^{14} \mathrm{C}\right]$ aminotriazole and $\left[{ }^{14} \mathrm{C}\right] \mathrm{glyphosate}$. Pestic. Sci. 18:55-64.

25. Moesta, P., and Grisebach, H. 1982. L- $\alpha$-Aminooxy- $\beta$-phenylpropionic acid inhibits phytoalexin accumulation in soybean with concomitant loss of resistance against Phytophthora megasperma f. sp. glycinea. Physiol. Plant Pathol. 21:65-70.

26. Nash, S. M., and Snyder, W. C. 1962. Quantitative estimation by plate counts of propagules of the bean root rot Fusarium in field soils. Phytopathology 52:567-572.

27. Neter, J., and Wasserman, W. 1974. Applied Linear Statistical Models. Irwin, Inc., Homewood, IL.

28. Padgette, S. R., Kolacz, K. H., Delannay, X., Re, D. B., LaVallee, B. J., Tinius, C. N., Rhodes, W. K., Otero, Y. I., Barry, G. F., Eichholtz, D. A., Peschke, V. M., Nida, D. L., Taylor, N. B., and Kishore, G. M. 1995. Development, identification, and characterization of a glyphosate-tolerant soybean line. Crop Sci. 35:1451-1461.

29. Powles, S. B., Lorraine-Colwill, D. F., Dellow, J. J., and Preston, C. 1998. Evolved resistance to glyphosate in rigid ryegrass (Lolium rigidum) in Australia. Weed Sci. 46:604-607.

30. Roy, K. W. 1997. Fusarium solani on soybean roots: Nomenclature of the causal agent of sudden death syndrome and identity and relevance of F. solani form B. Plant Dis. 81:259-266.

31. Roy, K. W., Rupe, J. C., Hershman, D. E., and Abney, T. S. 1997. Sudden death syndrome of soybean. Plant Dis. 81:1100-1111.

32. Rupe, J. C. 1989. Frequency and pathogenicity of Fusarium solani recovered from soybeans with sudden death syndrome. Plant Dis. 73:581584.

33. Scherm, H., and Yang, X. B. 1996. Development of sudden death syndrome of soybean in relation to soil temperature and soil water matric potential. Phytopathology 86:642-649.

34. Sharon, A., Amsellem, Z., and Gressel, J. 1992. Glyphosate suppression of induced defense responses: Increased susceptibility of Cassia obtusifolia to a mycoherbicide. Plant Physiol. 98: 654-659.

35. Smiley, R. W., Ogg, A. G., Jr., and Cook, R. J. 1991. Influence of glyphosate on Rhizoctonia root rot, growth, and yield of barley. Plant Dis. 76:937942 . 
36. Stephens, P. A., Nickell, C. D., Moots, C. K., and Lim, S. M. 1993. Relationship between field and greenhouse reactions of soybean to Fusarium solani. Plant Dis. 77:163-166.

37. Torstensson, N. T. L., Lundgren, L. N., and Stenstrom, J. 1989. Influence of climatic and edaphic factors on persistence of glyphosate and 2,4-D in forest soils. Ecotoxicol. Environ. Saf. 18:230-239.

38. Ward, E. W. B. 1984. Suppression of metalaxyl activity by glyphosate:
Evidence that host defense mechanisms contribute to metalaxyl inhibition of Phytophthora megasperma f. sp. glycinea in soybeans. Physiol. Plant Pathol. 25:381-386.

39. Yang, X. B., Sanogo, S., Uphoff, M., and Lundeen, P. 1998. Status, trends, and management of soybean sudden death syndrome and white mold. Pages 241-246 in: Proc. 10th Annu. Integr. Crop Manage. Conf. Iowa State University Extension, Ames. 